\title{
Seismic response of shear wall with viscous damping system
}

\begin{abstract}
Seismic response behavior of the shear wall buildings has been investigated since last few years in the seismic zones using laboratory experimental testing and commercial package analysis. Three-dimensional analysis of shear wall structure under multiple direction of seismic excitation is a challenging work in the design of earthquake resistance structure, but the most challenging task is the analysis of the shear wall equipped with viscous damper at the middle of the shear wall using three dimensions of time history earthquake excitations. The main objective of this research is to find out the optimum shear wall location under three dimensions of earthquake excitation using commercial package ETABS. For this purpose two models of shear wall locations have been adapted in this research. Model type one, the shear wall is located at the middle span of three spans frame. Model type two, the shear wall is located at the corner spans of the same frame. The other objective of this research is to find out the optimum viscous damper location under three dimensions of earthquake excitation using commercial package ETBS. So, four different location of the viscous damper has been adapted in both two different shear wall models where the viscous damper embedded cut out of shear wall. The result of the peak deflection and structural member forces of the both shear wall models with and without implementation of viscous damper has been obtained successfully and compared their results accordingly. The result indicates the best performance of the shear wall goes to model type two. On the other hand, when the viscous damper located at the top of the shear wall frame structure has achieved the highest percentage reduction of the tip deflection and structural member forces of the shear wall frame and it is optimum location of viscous damper under 3D earthquake.
\end{abstract}

Keyword: 3D earthquake; Shear wall; Viscous damper; Time history 